\title{
Ventromedial Prefrontal Cortex Lesions Produce Early Functional Alterations during Remote Memory Retrieval
}

\author{
Asaf Gilboa, ${ }^{1,2}$ Claude Alain, ${ }^{3,4}$ Yu He, ${ }^{3}$ Donald T. Stuss, ${ }^{3,4,5}$ and Morris Moscovitch ${ }^{3,4}$ \\ ${ }^{1}$ Department of Psychology, University of Haifa, Haifa 31905, Israel, ${ }^{2}$ Cognitive Neurology Unit, Rambam Medical Center, Haifa 31096, Israel, ${ }^{3}$ Rotman \\ Research Institute, Baycrest Centre, Toronto, Ontario, Canada M6A 2E1, and ${ }^{4}$ Departments of Psychology and ${ }^{5}$ Medicine (Neurology, Rehabilitation \\ Science), University of Toronto, Toronto, Ontario, Canada M5S 3G3
}

We examined the role of ventromedial prefrontal cortex (VMPFC) in memory retrieval monitoring. Event-related potentials were recorded while patients with VMPFC lesions and matched controls viewed faces of personal acquaintances, and of famous and nonfamous people, and indicated whether they had personally encountered these individuals. Patients were more likely than controls to make both false positive and false negative errors. Both groups showed a large posterior negative wave peaking at $\sim 170 \mathrm{~ms}$ after face onset (N170). In controls, the $\mathrm{N} 170$ was larger for both types of familiar faces, regardless of whether overt recognition occurred. Specifically, personal acquaintances that were erroneously judged as unfamiliar evoked the same electrophysiological response as those who were explicitly recognized. Patients' N170 was not modulated by familiarity suggesting VMPFC lesions disrupt early posterior memory-based preconscious cortical distinctions. Following the N170, there was a significant group difference over frontopolar scalp regions where patients were showing a smaller positive modulation at $230-260 \mathrm{~ms}$ for all stimulus types. In patients this modulation correlated highly with reaction times of correct responses, suggesting this early frontal modulation is related to the ability to make rapid correct decisions about memory content. Group differences over anterior sites were also noted at $350 \mathrm{~ms}$ after stimulus, reflecting a large sustained negativity of patients' waveforms, equal across conditions. The findings are consistent with a hypothesis of frontally mediated dual-monitoring system. An early automatic (preconscious) component is followed by a late elaborate process. We hypothesize that when both components are damaged, confabulation may occur.

\section{Introduction}

The reconstructive nature of memory makes it vulnerable to errors and distortions (Schacter et al., 1998). Structures within the prefrontal cortex (PFC) are crucial for reducing or avoiding false memories through strategic processes such as retrieval cue generation and output monitoring (Fletcher and Henson, 2001; Moscovitch and Winocur, 2002; Rugg et al., 2002). The ventromedial PFC (VMPFC), which is densely connected through limbothalamic pathways with the amygdala and hippocampus, is the prefrontal subregion most involved in mnemonic functions while dorsolateral prefrontal cortex (DLPFC) together with posterior parietal heteromodal cortex appear to form an executive/ attention functional axis (Mesulam, 2000). Data from monkeys (Mishkin et al., 1984) and humans (DeLuca and Diamond, 1995) suggest that primary memory impairments following VMPFC lesions result from damage encroaching on the basal forebrain. Lesions restricted to the VMPFC itself affect memory monitoring (Moscovitch and Winocur, 2002; Gilboa, 2004), which are complex evaluative processes used to avoid memory errors (Koriat et

\footnotetext{
Received 0ct. 28, 2008; revised March 6, 2009; accepted March 12, 2009.

This research was conducted with support from the Canadian Foundation for Innovation/Ontario Innovation Trust Grant 1226 and the Heart and Stroke Foundation (entre for Stroke Recovery. A.G. is supported by a European Union FP06 Marie Curie International Reintegration Grant (046544).

Correspondence should be addressed to Dr. Asaf Gilboa, Psychology Department, University of Haifa, Mount Carmel, Haifa 31905, Israel. E-mail: agilboa@psy.haifa.ac.il.

D01:10.1523/JNEUROSCI.5210-08.2009

Copyright $\odot 2009$ Society for Neuroscience $\quad$ 0270-6474/09/294871-11\$15.00/0
}

al., 2000), or memory filtering (Schnider, 2003), which is the suppression of currently irrelevant activated memory traces. The VMPFC's precise role in monitoring or filtering has yet to be determined.

The prefrontal cortex mediates at least two types of memory monitoring and filtering. One is a conscious, deliberate, rational process akin to problem solving in other domains [dubbed by Burgess and Shallice (1996) the "editor"], which crucially depends on the DLPFC. Conversely, the VMPFC is hypothesized to mediate a phenomenological "feeling of rightness" (FOR): the ability to appreciate rapidly or intuitively the appropriateness and accuracy of a response with relation to current personal goals (Gilboa and Moscovitch, 2002; Moscovitch and Winocur, 2002). FOR precedes elaborate cognitive verification of memory veracity and context appropriateness, and is impenetrable to rational influences, suggesting it is formed outside of conscious awareness and may be affectively laden. Gilboa (2004) proposed that FOR partially depends on a correspondence between memory cues and long-term memory representations, which should emerge very early in processing to serve as a basis for FOR. These ideas of FOR in the memory domain are closely associated with more general functions of the VMPFC in emotion-based decision making (Bechara et al., 2000a) or processing of reinforcement contingencies based on the individual's current goals (Schnider et al., 2002; Rolls, 2004).

Event-related potentials (ERPs) have the temporal resolution required to detect the neural signature of rapid preconscious pro- 


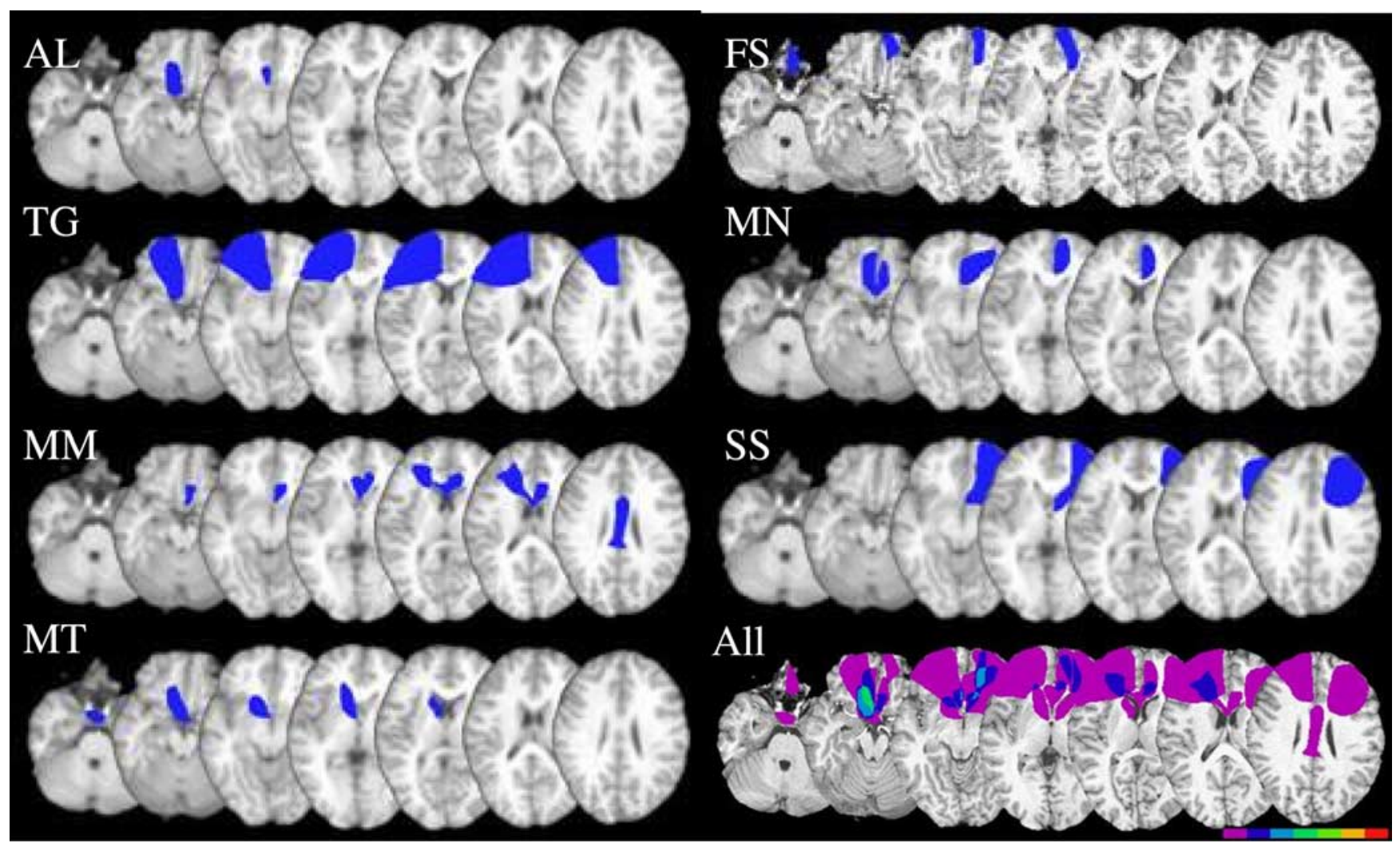

Figure 1. Lesion locations of 7 of the 8 ACoA patients drawn from clinical CTs and superimposed on a template MRI scan. The last image (All) shows lesion overlap across patients, with the color bar reflecting the number of patients with overlapping lesions at a particular location. Color bar for the bottom right figure represents the number of patients whose lesion overlaps at a particular location with a minimum of one (purple) to a maximum of seven (red). The image was created using MRIcro software (Chris Rorden; www.psychology.nottingham.ac.uk/staff/cr1/mricro.html).

cesses such as FOR. Electrophysiological studies of amnesia have reported primarily late recollection-related posterior ERP modulations on anterograde (recent) memory tests following hippocampal/diencephalic lesions (Mecklinger et al., 1998; Olichney et al., 2000; Taylor and Olichney, 2007). FOR, however, is most obvious in autobiographical (remote) memory (Brewer, 1986), and is disrupted by VMPFC lesions. We examined the dualmonitoring system hypothesis by measuring ERPs in patients with focal VMPFC lesions and matched healthy controls during speeded decisions about remote memory representations for faces of famous, personally familiar, and unfamiliar people. FOR disruption following VMPFC lesions, should be reflected by very early anterior electrophysiological group differences which would predict memory accuracy and decision speed.

\section{Materials and Methods \\ Participants}

Eight patients with lesions to the VMPFC following rupture of an ACoA aneurysm were recruited from Baycrest Hospital Psychology Department and the Rotman Research Institute's patient registry. These were all the patients with a diagnosis of ACoA aneurysm rupture who were treated at the Baycrest Psychology Department at the time, or whose name appeared on the Rotman's registry. Eight healthy controls matched for age, gender, and education were recruited from the Rotman Research Institute's healthy volunteer pool. CTs and/or MRIs were obtained for seven of the ACoA patients. Seven of the eight patients had neurosurgical intervention for clipping the aneurysm. We identified the specific frontal regions that were damaged in each patient (Fig. 1) by superimposing their individual scans on a brain template based on previously published guidelines (Stuss et al., 2002). Lesions were drawn by the primary author, and for verification and replication, they were independently drawn by D.T.S. and Dr. Michael Alexander from Harvard Medical School (Bos-
Table 1. Demographics of VMPFC patients and healthy controls

\begin{tabular}{lll}
\hline & ACoA patients $(n=8)$ & Healthy controls $(n=8)$ \\
\hline Gender (M/F) & $5 / 3$ & $4 / 4$ \\
Handedness (R/L) & $6 / 2$ & $7 / 1$ \\
Age (years) & $51.12(11.44)$ & $54.5(12.13)$ \\
& $(38-68)$ & $(33-65)$ \\
Education (years) & $15.75(2.76)$ & $16.5(2.72)$ \\
& $(11-18)$ & $(12-20)$ \\
Estimated IQ (Shipley) & $103.25(10.00)$ & $106.37(9.86)$ \\
& $(90-119)$ & $(91-117)$ \\
Months since loss & $21.37(27.44)$ & \\
& $(4-86)$ & \\
\hline
\end{tabular}

Numbers in parentheses to the right of the mean are SDs; numbers in parentheses below the mean and SD are ranges.

ton, MA). Where there were differences, the latter's delineation of the lesion was used.

Patients and controls were matched for age, years of education, sex, handedness, and estimated IQ based on performance on the Shipley Institute of Living Scale (Table 1). Patients ranged with regard to the time since injury from 4 months to more than eight years after surgery with the average being $\sim 2$ years (Table 1 ).

Patients had varying degrees of executive and anterograde memory impairments as determined by neuropsychological testing (Table 2), but all were at least moderately impaired on one domain of memory (delayed verbal or delayed visual memory) and/or had executive dysfunction (Fig. 2). Retrograde memory, as measured by the Autobiographical Memory Interview (AMI) (Kopelman et al., 1990), was within normal range for both episodic (event) memory and personal semantic facts (Table 2). In contrast, for anterograde (recent) autobiographical memory there was more variation across patients, with some of them showing impairments on both parts of the AMI. 
Table 2. Neuropsychological performance of patients with VMPFC damage

\begin{tabular}{|c|c|c|}
\hline & Mean (SD) & Range \\
\hline \multicolumn{3}{|l|}{ Executive/attentional } \\
\hline WCST categories & $3.71(1.80)$ & $1.00-6.00$ \\
\hline Number of errors $(Z)$ & $-0.51(0.96)$ & -1.75 to 0.87 \\
\hline \% Persev. errors (Z) & $-0.59(1.32)$ & -2.7 to 1.05 \\
\hline \multicolumn{3}{|l|}{ Fluency } \\
\hline Phonemic (Z) & $-0.97(1.59)$ & -2.93 to 1.22 \\
\hline Semantic (Z) & $-0.84(1.45)$ & -2.76 to 0.94 \\
\hline \multicolumn{3}{|l|}{ SDMT } \\
\hline Oral (Z) & $-0.29(0.83)$ & -1.65 to 0.68 \\
\hline Written $(Z)$ & $0.09(1.20)$ & -1.89 to 1.37 \\
\hline \multicolumn{3}{|l|}{ TMT } \\
\hline Part A (Z) & $-0.87(1.31)$ & -2.33 to 0.85 \\
\hline Part B (Z) & $-1.38(1.58)$ & -2.88 to 0.62 \\
\hline \multicolumn{3}{|l|}{ Anterograde memory } \\
\hline \multicolumn{3}{|l|}{ WMS III } \\
\hline LM1 (SS) & $7.25(2.31)$ & $4.00-11.00$ \\
\hline LM2 (SS) & $7.13(2.70)$ & $4.00-13.00$ \\
\hline VPA1 (SS) & $5.75(3.69)$ & $1.00-12.00$ \\
\hline VPA2 (SS) & $6.50(3.34)$ & $3.00-13.00$ \\
\hline Recognition (SS) & $8.25(3.11)$ & $5.00-14.00$ \\
\hline \multicolumn{3}{|l|}{ RCFT } \\
\hline Immediate $(Z)$ & $-1.40(0.87)$ & -2.75 to -0.60 \\
\hline Delayed (Z) & $-1.70(0.79)$ & -2.75 to -0.92 \\
\hline \multicolumn{3}{|l|}{ RAVLT } \\
\hline Trial $1(Z)$ & $-1.35(1.28)$ & -2.68 to 0.37 \\
\hline Delayed (Z) & $-1.70(0.92)$ & -3.41 to 0.56 \\
\hline Delayed recognition (hits-FA) (Z) & $-1.33(1.20)$ & -3.20 to 1.54 \\
\hline \multicolumn{3}{|l|}{ Remote memory } \\
\hline \multicolumn{3}{|l|}{ AMI-EM } \\
\hline Childhood $^{a}$ & $7.00(1.58)$ & $5.00-9.00$ \\
\hline Early adulthood $^{a}$ & $7.40(1.82)$ & $5.00-9.00$ \\
\hline Recent (anterograde) ${ }^{b}$ & $5.00(3.16)$ & $0.00-8.00$ \\
\hline \multicolumn{3}{|l|}{ AMI-Sem. } \\
\hline Childhood ${ }^{c}$ & $19.40(1.34)$ & $18.00-21.00$ \\
\hline Early adulthood $^{d}$ & $19.30(1.03)$ & $18.00-20.50$ \\
\hline Recent (anterograde) ${ }^{e}$ & $16.30(5.68)$ & $8.50-21.00$ \\
\hline
\end{tabular}

The normative data for the tests were taken from the original manuals or from the sources referenced below. AMI The Autobiographical Memory Interview (Kopelman et al., 1990); AMI-EM, event memory; AMI-Sem., semantic memory; RAVLT, Rey's Auditory Verbal Learning Test; RCFT, Rey's Complex Figure Test; SDMT, Symbol Digit Modalities Test; TMT, Trails Making Test; WCST, Wisconsin Card Sorting Test; Persev., perseverations; WMS, Wechsle Memory Scale III; LM1, logical memory immediate; LM2, logical memory delayed; VPA1, verbal paired associates immediate; VPA2, verbal paired associates delayed; SS, scaled score (cutoff for abnormal, $\leq 4$ ); Z,Z zcore (cutoff for abnormal, $\leq-2$ ).

${ }^{a}$ Cutoff for abnormal, $\leq 3{ }^{b}$ cutoff for abnormal, $\leq 5{ }^{c}$ cutoff for abnormal, $\leq 11 ;{ }^{d}$ cutoff for abnormal, $\leq 14$; ${ }^{e}$ cutoff for abnormal, $\leq 17$.

One patient (FS) who was 7 years after his ACoA aneurysm rupture was still confabulating at the time of testing. Another patient (TG) was not actively confabulating, however he spontaneously described himself as having false memories which he did not trust and which had led him to be very cautious about his memory and consult his friends and relatives regularly about events he thought he remembered. In two other patients (FR and MN) a history of confabulations could be verified through interview with family members, clinicians, or the patients themselves. All procedures were approved by the Institutional Review Boards of Baycrest Hospital.

\section{Experimental design and materials}

The experimental stimuli were comprised of three kinds of faces: (1) personally familiar faces, (2) famous faces, and (3) unfamiliar faces.

Personally familiar faces. These were faces cropped out of pictures from family albums, covering the lifetime of the participant. Only pictures in which the participant appeared were used so as to ensure that all of the persons represented in the picture were familiar. Still familiarity of the faces varied, as some of the faces were of close relatives whereas others could be of old school teachers, classmates, work colleagues, etc. Moreover, faces of relatives could be taken from different periods of the par- ticipant's life (e.g., a childhood picture of a sibling). The same person's face could serve as a stimulus up to twice, provided that pictures from very different time periods were used (i.e., separated by at least 20 years). Because of the difficulty of obtaining stimuli for the personally familiar faces, the number of stimuli to which participants were exposed varied somewhat among participants (average: $133.56, \mathrm{SD}=16.82$, range: $108-$ 156). There was no consistent group difference in the overall number of photos $\left(t_{(14)}=-1.41 ; p>0.05\right)$ between controls $(M=129.37$; $\mathrm{SD}=$ $12.69)$ and patients $(M=137.75 ; \mathrm{SD}=11.01)$. The vast majority of photographs were scanned at $300 \mathrm{dpi}$; when this was not possible due to a photo's low quality; it was scanned at the highest quality possible. Photos that were originally taken in color were turned into grayscale using commercially available software (Adobe Photoshop).

Famous faces. There were 115 faces of famous personalities, who were selected out of a larger set of 250 faces, based on a pilot study with 20 middle-aged individuals. The faces were scanned out of journal magazines or downloaded from the internet. We attempted to use photographs of famous people in naturalistic poses so as to match the faces from the other conditions. In all conditions faces could be in full frontal view, half views, profiles, etc., and faces could express emotion, reflect a speech act, etc. Additionally, we purposely selected a portion of the pictures of famous faces which were of low quality (blurry, dark, etc.) so as to mimic the faces from family members and acquaintance, which were sometimes taken out of very old or low quality pictures. During the pilot study, participants were asked to rate each of the faces for familiarity, as well as provide some identifying detail if they could as to the identity of the person (name, reason for fame, etc.). Only faces that at least $90 \%$ of the pilot participants had identified as famous were selected, although faces varied with regard to the average level of familiarity ratings they received.

Unfamiliar faces. Participants also viewed 120 faces of unfamiliar people, who were selected out of the personal stimuli of other participants. There were faces of people of different chronological ages and from different decades so as to match the distribution of personally familiar and famous faces.

\section{Task and procedures}

Participants were told that they would view faces of people from their personal pasts, faces of famous personalities, and faces of unfamiliar people. They were told that they should respond with "yes" (left mouse button; pointing finger) only for people they had personally encountered and with "no" (right mouse button; middle finger) for all others, regardless of whether they know who they are or not. Each trial was preceded by a fixation with the question "Have you personally met this individual before?" and mapping of the response buttons at the bottom, which appeared for $1000 \mathrm{~ms}$. The question and mapping of the buttons remained on screen the whole time. Following fixation, the faces appeared for $600 \mathrm{~ms}$ and after the face disappeared, participants had a time window of up to $2000 \mathrm{~ms}$ to respond, following which the next trial automatically began (Fig. 3). Participants were encouraged to respond as quickly as possible but not at the expense of accuracy.

Following the application of the electrode cap, the experiment was run within a single session lasting $\sim 10-12 \mathrm{~min}$. A pause was included midway through the session (after $\sim 140$ stimuli, depending on the number of personally familiar faces). During the break the experimenter entered the chamber to speak to the participants, to ensure they were not too fatigued and to encourage them. Participants in fact reported enjoying the experiment, and in particular they reported enjoying seeing faces of persons they had not thought about in a long time.

\section{ERP recordings and analysis}

Continuous EEG was recorded with Neuroscan software using a Synamps neural amplifier (Compumedics) and 64-channel tin electrode caps (Electro-Cap International), with electrodes placed according to the 10-20 system (Jasper, 1958). EEG recordings were made at a sample rate of $500 \mathrm{~Hz}$, using a $\mathrm{Cz}$ reference. The continuous EEG recordings were filtered on line between 0.05 and $100 \mathrm{~Hz}$. During the recording, electrodes placed at the outer canthi and the superior and inferior orbit monitored vertical and horizontal eye movements. 


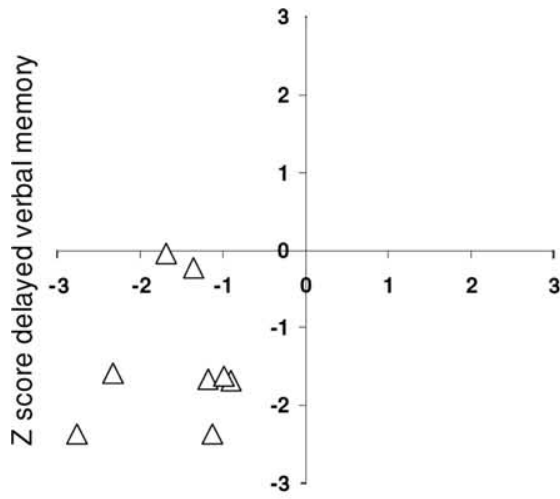

Z score delayed visual memory

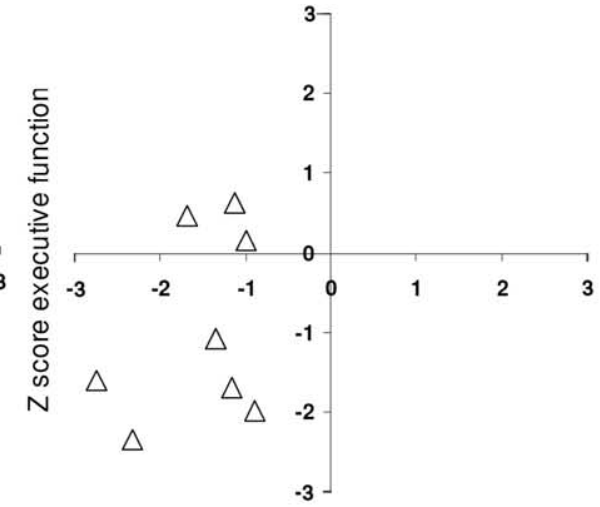

Z score delayed visual memory

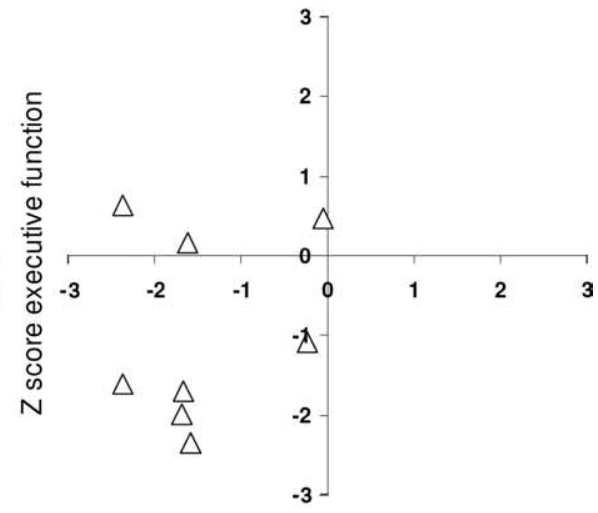

Z score delayed verbal memory

Figure 2. Scatter plots of average Z scores on delayed verbal memory (Logical memory II, Verbal Paired Associates II, Rey Auditory Verbal Learning Test Delayed), Z score on the delayed Rey-0stereith Complex Figure Test, and average Z score on Executive Function Tests (Wisconsin Card Sorting Test errors and perseverations, phonemic fluency, and Trail Making Test B).

The continuous EEG files were segmented into $700 \mathrm{~ms}$ epochs including a $100 \mathrm{~ms}$ prestimulus window and the time of stimulus visual presentation. These epochs were then rereferenced to a common-average reference, and baseline corrected over the prestimulus window. Trials contaminated by excessive peak-topeak deflection (exceeded $\pm 150 \mu \mathrm{V}$ ) at the channels not adjacent to the eyes were automatically rejected. The remaining epochs were then sorted and averaged so that for each participant, each type of face and accuracy of response had their own average [i.e., hits and misses for personally familiar faces; correct rejection (CR) and false alarms (FA) for famous faces, and CR and FA for unfamiliar faces]. Across healthy participants, the number of included trials for hits, CRs famous and CRs nonfamous varied

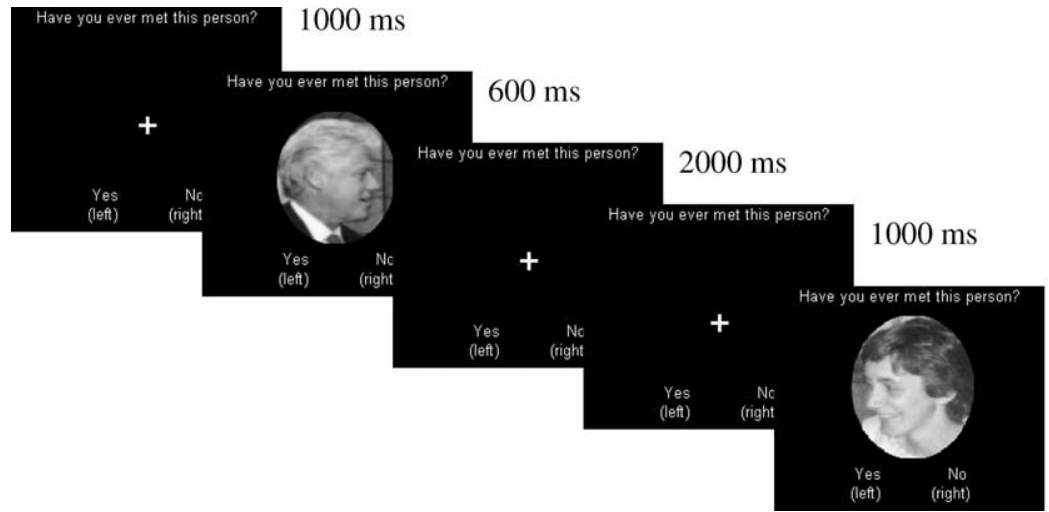

$600 \mathrm{~ms}$

Figure 3. Experimental design with examples of a famous personality and a family member. Note that the response frame was terminated by participants' responses, and so lasted only $300-400 \mathrm{~ms}$ on average rather than $2000 \mathrm{~ms}$ (see Results, Behavioral data).

\section{between 68 and 122 for each category. FAs were}

not included as there were very few such events. For the patients, the number of included trials for hits, CRs famous and CRs nonfamous varied between 36 and 116 for each category.

For each participant, a set of ocular movements was obtained before and after the experiment (Picton et al., 2000). From this set, averaged eye movements were calculated for both lateral and vertical eye movements as well as for eyeblinks. A principal component analysis of these averaged recordings provided a set of components that best explained the eye movements. The scalp projections of these components were then subtracted from the experimental ERPs to minimize ocular contamination such as blinks, saccades, and lateral eye movements for each individual average. ERPs were then digitally low-pass filtered to attenuate frequencies of $>20 \mathrm{~Hz}$. ERP amplitudes were measured relative to the mean amplitude over the prestimulus interval.

The effects of VMPFC lesions on face processing and memory decisions were examined on the P1, N170, and P2 waves. The P1 mean amplitude was quantified over the $90-110 \mathrm{~ms}$ interval at occipital (O1 and $\mathrm{O} 2$ ) and cerebellar ( $\mathrm{CB} 1$ and $\mathrm{CB} 2$ ) electrodes in line with previous research on face perception (Caharel et al., 2002, 2006; Jemel et al., 2003; Itier and Taylor, 2004; Jemel et al., 2005; Anaki et al., 2007). Similarly, the effect of lesion and familiarity on the mean amplitude of the face sensitive N170 (Bentin and Deouell, 2000; Caharel et al., 2002, 2006, 2007; Rossion and Gauthier, 2002; Jemel et al., 2003, 2005; Itier and Taylor, 2004; Anaki et al., 2007; Marzi and Viggiano, 2007) was quantified over the 150-190 $\mathrm{ms}$ interval at inferior parietal (P7 and P8) and cerebellar (CB1 and CB2) electrodes. The P2 mean amplitude wave was measured for the 280-320 ms interval at occipital (O1 and O2) and cerebellar (CB1 and CB2) electrodes. The effects of VMPFC lesions on ERPs recorded during the face recognition task were also examined for the $230-260 \mathrm{~ms}$ interval at frontopolar electrodes (FP1, FPz, FP2). This interval was chosen to ease com- parison with a prior ERP study which examined performance of healthy adults on a task known to be sensitive to confabulation (Schnider et al., 2002) as well as with prior research on face recognition showing early memory-related activity for faces peaking at $\sim 250 \mathrm{~ms}$ at frontocentral and frontopolar scalp region (Guillaume and Tiberghien, 2005). Moreover, intracerebral recordings in humans with intractable epilepsy have revealed early visual evoked responses to faces in prefrontal cortex (Halgren et al., 1994; Klopp et al., 2000). Hence, we seek to determine whether VMPFC lesions would attenuate early responses to faces over the frontal scalp region. Another modulation of interest was also measured, namely, the sustained potential over the frontocentral and frontopolar scalp regions. The sustained potential was quantified over the 450-550 ms interval at frontopolar sites $(\mathrm{FP} 1, \mathrm{FPz}, \mathrm{FP} 2)$, again to facilitate comparison with the study by Schnider et al. (2002) and previous face-processing studies. The mean amplitude measurements were analyzed using repeated-measure ANOVAs with group as the between-subject factor and stimulus type as determined by response accuracy (i.e., hit, miss, correct rejections of famous faces and correct rejections of nonfamous faces) as the within-subjects factor.

\section{Results}

\section{Behavioral data}

Because the VMPFC is thought to be involved in memory processes, it was hypothesized that patients would show a reduced ability at distinguishing faces of persons from their own past and other faces. As Figure $4 A$ illustrates, hit rate was lower than correct rejections with patients performing worse than controls. This impression was confirmed by ANOVA which showed a significant within-subject main effect of accuracy $\left(F_{(2,28)}=15.01, p<\right.$ 
A.
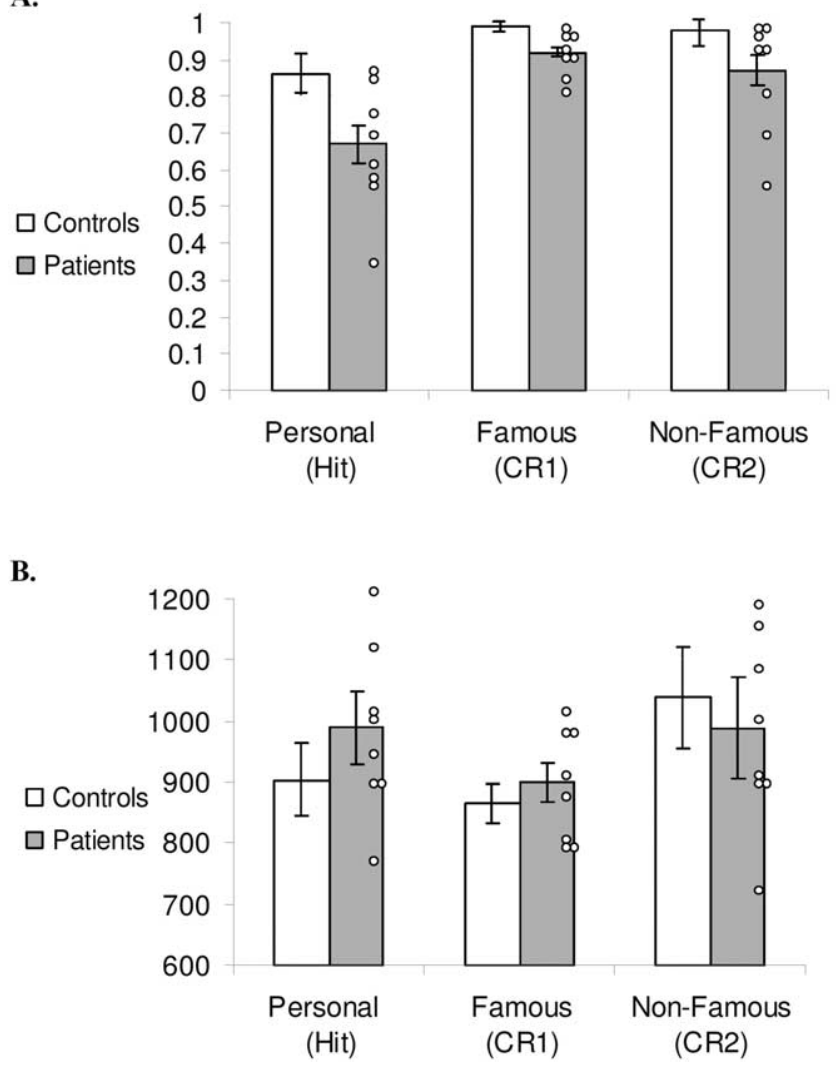

Figure 4. Accuracy rates $(\boldsymbol{A})$ and reaction times $(\boldsymbol{B})$ for hits for personally familiar faces, correct rejections of famous faces, and correct rejections of nonfamous faces. Error bars represent SEs. Individual patients' scores are noted by white circles.

$0.01)$, with no accuracy-by-group interaction $\left(F_{(2,28)}=1.44, p>\right.$ 0.05). Post hoc contrasts indicated that hit rate was significantly lower than correct rejections of famous $\left(F_{(1,14)}=22.8, p<0.01\right)$ and nonfamous $\left(F_{(1,14)}=13.36, p<0.01\right)$ faces. Correct rejection rates of famous and nonfamous faces did not differ significantly from each other $\left(F_{(1,14)}=1.26, p>0.05\right)$, although both figures show a ceiling effect and this result needs to be considered cautiously. There was also a significant between-subject group main effect $\left(F_{(1,14)}=14.21, p<0.01\right)$, reflecting the overall lower accuracy of patients compared with controls on this task.

We also computed $d^{\prime}$ scores for patients and controls, separately for famous faces false alarms and unfamiliar faces false alarms in relation to family faces hits. Patients' average $d^{\prime}$ scores were generally lower with famous faces serving as baseline (patients: $d^{\prime}=1.97$, range: $1.32-3.39$; controls: $d^{\prime}=4.03$, range: $3.01-4.65 ; t_{(14)}=4.89, p<0.01$ ), with no difference in bias between groups (patients: normalized $C=0.29$; controls: normalized $\left.C=0.16 ; t_{(14)}=-1.39, p>0.05\right)$. With respect to the $d^{\prime}$ scores when unfamiliar faces serve as baseline, results were similar. Patients' average $d^{\prime}$ scores were generally lower for both famous faces (patients: $d^{\prime}=2.11$, range: $0.71-4.54$; controls: $d^{\prime}=$ 3.31 , range: $\left.2.34-4.65 ; t_{(14)}=2.17 ; p<0.05\right)$, with no difference in bias for patients (normalized $C=0.25$ ) compared with controls (normalized $C=0.13 ; t_{(14)}=-0.95 ; p>0.05$ ).

Figure $4 B$ shows that both patients and controls could reject famous faces more quickly than familiar faces, and reject unfamiliar ones more quickly than they could endorse family faces. This impression was supported by ANOVA which indicated a main effect of familiarity on reaction time $(\mathrm{RT})\left(F_{(2,28)}=3.92\right.$, $p<0.05)$, with no RT-by-group interaction $\left(F_{(2,28)}=1.08, p>\right.$ $0.05)$. Contrasts indicated that participants were faster for correct rejections of famous faces than correct rejections of unfamiliar faces $\left(F_{(1,14)}=6.53, p<0.05\right)$ and RTs to hits for family faces were longer than to correct rejections of unfamiliar faces $\left(F_{(1,14)}\right.$ $=5.25, p<0.05)$. Importantly, there were no significant between-group differences in $\mathrm{RT}\left(F_{(1,14)}=0.30, p>0.05\right)$ which could confound a comparison of the ERPs.

\section{ERP results}

Our neuropsychological model predicts three primary ERP patterns: (1) very early frontally distributed differences between patients and controls that would reflect FOR processes. (2) These should rely on a preceding signal reflecting a concordance between a memory cue (picture of a face) and a long-term memory representation that should occur over posterior cortices where the cue is being processed and supposedly LTM representations are stored. (3) Finally, a later frontally distributed component is expected to reflect conscious monitoring of retrieval products. Next we describe the primary ERP waveforms over posterior sites, followed by the waveforms over anterior sites.

\section{Posterior sites}

Figure 5 shows the group mean ERPs elicited by personally familiar, unfamiliar, and famous faces in both patients with a VMPFC lesion and age-matched controls. In both groups, faces elicited a clear P1, N1 (N170), and P2 waves at inferior occipital-temporal-parietal sites. The P1 mean amplitude $(90-110 \mathrm{~ms})$ showed no main effect of hemisphere $\left(F_{(1,14)}=0.09, p>0.05\right)$, stimulus type $\left(F_{(3,42)}=0.55, p>0.05\right)$, or group $\left(F_{(1,14)}=0.29, p>0.05\right)$, and none of the interactions was significant (Fig. 5A,B).

Numerous ERP studies have described a face-sensitive right lateralized $\mathrm{N} 1$ component peaking at $\sim 170 \mathrm{~ms}$ after stimulus onset (Bentin and Deouell, 2000; Caharel et al., 2002, 2006, 2007; Rossion and Gauthier, 2002; Jemel et al., 2003, 2005; Itier and Taylor, 2004; Anaki et al., 2007; Marzi and Viggiano, 2007). A clear N170 component was recorded over the inferior parietal and cerebellar sites on both right (i.e., CB2 and P8) and left (i.e., $\mathrm{CB} 1, \mathrm{P} 7)$ hemispheres. The average N170 over right-sided electrodes was larger than that measured over left-sided electrodes $\left(F_{(1,14)}=6.22 ; p<0.05\right)$ with no significant group differences $\left(F_{(1,14)}=1.24 ; p>0.05\right)$ and a side-by-group interaction only approached significance $\left(F_{(1,14)}=3.24 ; p=0.09\right)$.

Examination of the effect of response type (hit, miss, famous, and nonfamous correct rejections) on the N170 for each side separately revealed no significant between-group effects (right: $F_{(1,14)}=2.23 ; p>0.05$; left: $\left.F_{(1,14)}=0.46 ; p>0.05\right)$ or overall condition effect (right: $F_{(3,42)}=1.32 ; p>0.05$; left: $F_{(3,42)}=0.68$; $p>0.05)$. There was, however, a significant group $\times$ condition interaction over right-sided electrodes $\left(F_{(3,42)}=3.91, p<0.05\right)$. Planned contrasts showed that this was the result of the unfamiliar faces correct rejections (CR2) amplitude being significantly lower than correct rejections of famous faces, hits of personal acquaintances, and misses of personal acquaintances $\left(F_{(1,14)}=\right.$ 5.18; $p<0.05$ ) (Fig. 5, arrow).

Thus, the normal controls' waveforms suggest a distinction between familiar (whether personally familiar or famous personalities) and nonfamiliar faces. The normal controls' waveforms for misses are particularly interesting, as they suggest familiarity with faces previously encountered that is not reflected by performance. It is also interesting to note that the patients do not show a distinction between familiar and nonfamiliar faces. These results are compatible with the second pattern predicted by our 
model which suggests a very early posterior signal which could code the correspondence between memory cues and long-term memory representations.

Significant group differences were revealed for the $\mathrm{P} 2$ wave over posterior sites bilaterally. Patients showed a larger P2 wave than controls averaged over left (O1, $\mathrm{CB} 1)$ and right $(\mathrm{O} 2, \mathrm{CB} 2)$ occipital areas $\left(F_{(1,14)}=37.33, p<0.05\right)$ with no laterality or interaction effects. There was also an overall response type effect $\left(F_{(3,42)}=5.11\right.$; $p<0.05)$. Pairwise comparisons with Bonferroni correction revealed that the P2 associated with unfamiliar faces was larger than the $\mathrm{P} 2$ associated with hits and misses of acquaintances' faces, whereas famous faces fell somewhere in the middle. There were no significant interactions between response type and either group or side.

Anterior sites

The waveforms over anterior sites were markedly different between patients and controls (Fig. 6). As predicted by our model there were significant group differences very early on, immediately following the posterior familiarity-sensitive N170, which may reflect the automatic FOR, and also at a later time window which may be associated with more controlled processes.

Patients showed a distinct N1, P1, and $\mathrm{N} 2$, which mirrored the pattern recorded over posterior sites but inverted in polarity and showing later latencies whereas controls showed the N1 and P1 which was followed by a sustained positivity. For the N1 measured over the frontopolar scalp region (averaged over FP1, FPz, FP2; $140-$ $160 \mathrm{~ms}$ after onset) there was no main effect of response type $\left(F_{(3,43)}=2.12, p>\right.$ $0.05)$, group $\left(F_{(1,14)}=0.238, p>0.05\right)$, or group-by-response interaction $\left(F_{(3,42)}=\right.$ $1.72 ; p>0.05$ ).

There was, however, a very early significant difference between patients with VMPFC lesions and controls associated with the positive modulation at frontopolar sites. This positive modulation peaked between 230 and $260 \mathrm{~ms}$. Healthy controls showed greater positivity than patients $\left(F_{(1,14)}=5.80 ; p<0.05\right)$ for this component, with no significant within-subject response-type effect $\left(F_{(3,42)}=2.02 ; p>\right.$ $0.05)$ or group-by-condition interactions $\left(F_{(3,42)}=1.04 ; p>0.05\right)$.

To assess the probability that this waveform difference obtained over anterior electrodes in fact was generated by anterior cortical areas, we took the following approach for source analyses using the grand average data from the controls only. Patients' data were omitted from source analyses because breaches to the skull as a result from neurosurgery preclude source analysis of the ERPs measured at the surface. We first used the spatiotemporal

B.
CONTROLS
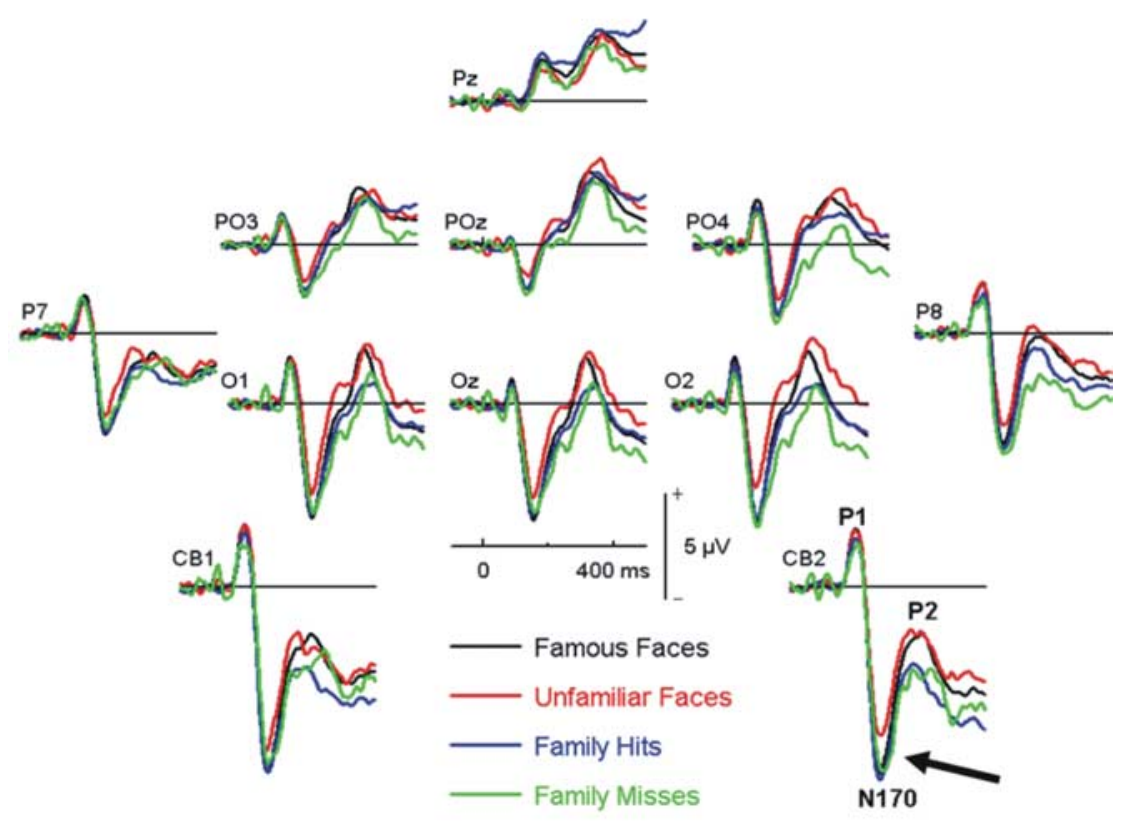

PATIENTS
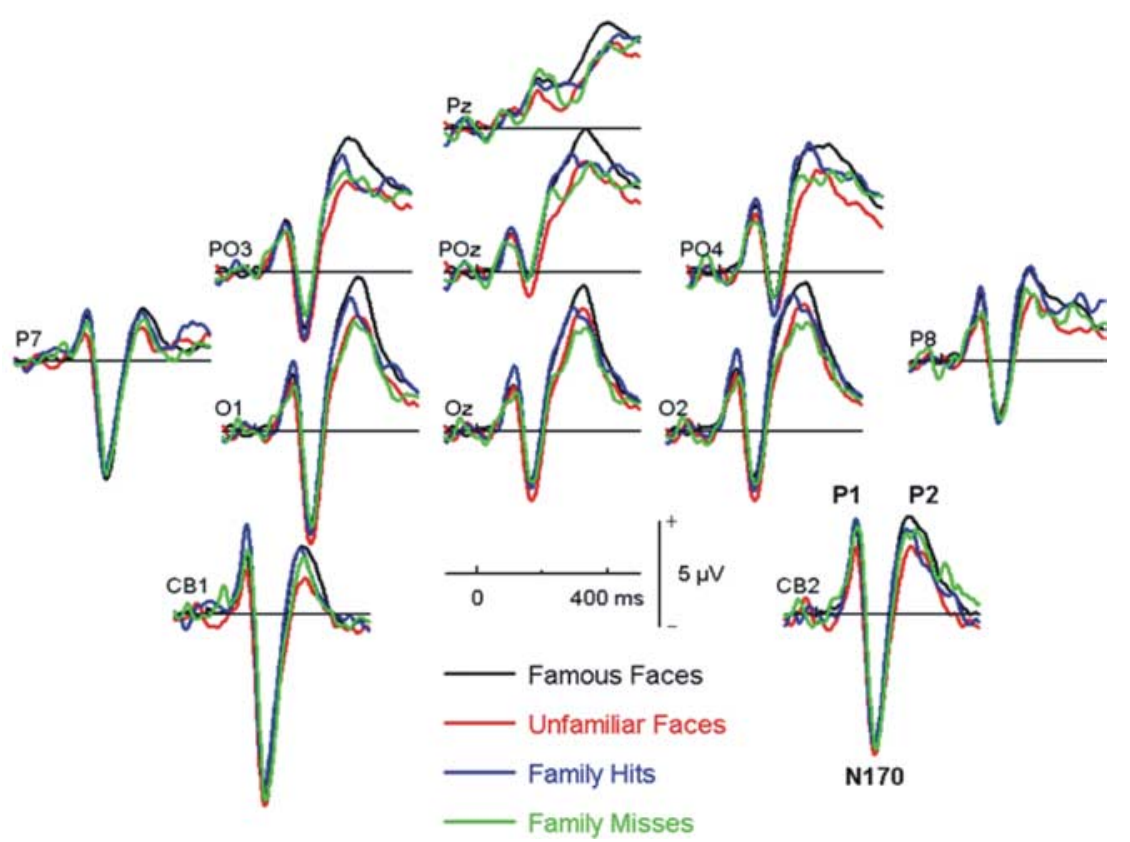

Figure 5. Group mean ERPs over posterior electrodes for correct rejections of famous faces (black), correct rejections of unfamiliar faces (red), hits of personal acquaintances (blue), and misses of personal acquaintances (green) for both controls ( $\boldsymbol{A}$ ) and patients $(\boldsymbol{B})$. Arrow indicates the significantly reduced $\mathrm{N} 170$ for unfamiliar faces in controls compared with all types of familiar faces regardless of explicit recognition.

multiple source analysis technique (implemented in the BESA 5.2 software). We modeled the visual sensory evoked responses (P1 and N170) using regional sources that were located in extrastriate and inferior temporal cortices which have been described in playing a major role in face perception. These were fixed to be symmetrical in each hemisphere. We then added two regional sources and forced them to be symmetrical. We fit these two sources to the group average data at the 230-260 ms time interval (where a significant difference was detected between patients and controls 

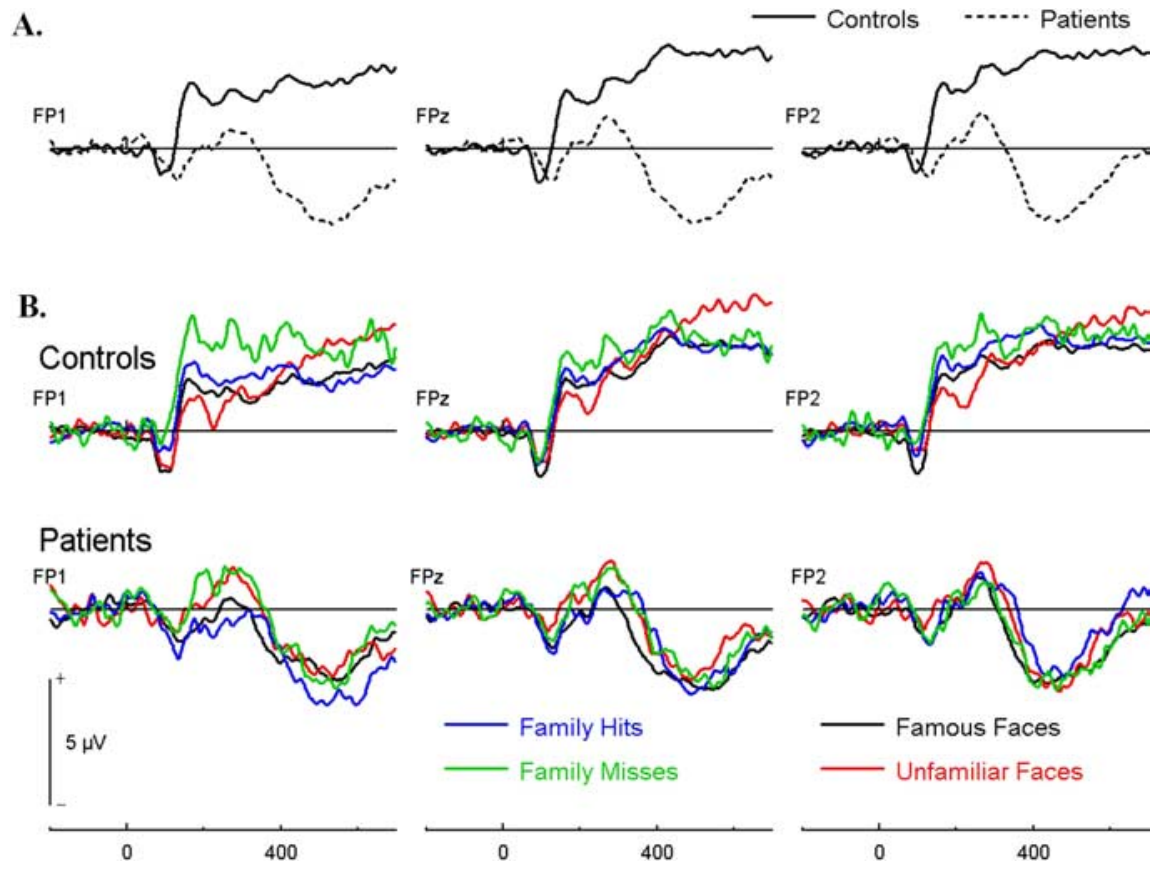

Figure 6. Group grand mean ERPs over frontopolar electrodes for patients and controls $(\boldsymbol{A})$ and separately for correct rejections of famous faces (black), correct rejections of unfamiliar faces (red), hits of personal acquaintances (blue), and misses of personal acquaintances (green) $(\boldsymbol{B})$.

over anterior electrodes). We kept the locations of the posterior sources, and optimized the location of the two regional sources, which yielded a location near the VMPFC $(\sim 1.5-2 \mathrm{~cm}$ from the area of maximum overlap of the patients' lesions). This model accounted for $97.2 \%$ of the variance (Fig. $7 A$ ).

We also used a different modeling approach. Local autoregressive average (i.e., LAURA) is a weighted minimum norm distributed source modeling implemented in BESA 5.2 software. This distributed approach does not require an a priori decision regarding the number of sources or their location. Applying the LAURA modeling approach for the $245 \mathrm{~ms}$ time point revealed bilateral frontal ventromedial sources that overlapped with and were even more ventromedial than the sources obtained with the spatiotemporal multiple source analysis technique (Fig. 7B) and was $\sim 1 \mathrm{~cm}$ away from the area of maximum overlap of the patients' lesions (Fig. 7C). Thus, both an overdetermined (dipolar) and an underdetermined (distributed) source models provided almost the same solution and both models located the generators of the early anterior ERP modulation to the ventromedial prefrontal cortex, where the patients' lesions had the most overlap. Together, these inverse solutions provide good evidence that the positive anterior modulation seen in controls but missing in patients may receive substantial contributions from the VMPFC in addition to possible other regions. The source waveforms (Fig. $7 D$ ) show the time course of source activity over posterior and anterior regions. As expected, very early sensory processes are best reflected by occipitotemporal sources followed by later activity (beginning at $\sim 200 \mathrm{~ms}$ ) which is best reflected in frontal areas.

Based on these models one could argue that the reduced amplitude in patients is related to the lesions sustained in that area. The correspondence between lesions in patients and ERP source in controls, provide evidence from different neuroscience approaches as to the role of the VMPFC in memory retrieval. Although multiple models may account for the data, this model accounts well to the data in controls, and converges with the lesion data.

Following the positive modulation, controls showed a brief negativity followed by a sustained positivity whereas patients showed a clear negative wave that followed in latency the P2 wave recorded at occipital sites, which led to a significant sustained late between-group difference over frontopolar sites, beginning at $\sim 350 \mathrm{~ms}\left(F_{(1,14)}\right.$ $=11.90, p<0.05)$. There were no significant within subject response type effect or response-by-group interaction effect, $F<$ 1 in both cases.

\section{Correlations between performance and} electrophysiological data

To explore the behavioral significance of the waveform differences between patients and controls, we examined the relationships between performance and electrophysiological data using reaction times for both groups and accuracy for the patients only (accuracy data could not be used in controls for famous and unfamiliar faces because of ceiling effects). Correlations were computed for the waveform components where significant group or condition effects were observed, separately for controls and patients for hits, correct rejections of famous personalities, and correct rejections of unfamiliar persons.

There were no significant correlations between response times and N170 amplitudes (Table 3). Significant negative correlations were present between early frontal amplitudes and hits and correct rejections of both types in the patients, but not in controls (Table 3, Fig. 8). Thus, patients with faster reaction times presented with a very early frontally distributed more positive deflection, closer to that exemplified by controls. This is consistent with the idea that this early frontal component is related to the ability to make rapid and accurate decisions about retrieved memory representations. Interestingly, the three patients who consistently showed the most negative waveforms for this early anterior ERP component were FS who still actively confabulated, TG who has erroneous memories which he does not relay and $\mathrm{MN}$ with a verified history of confabulation.

There was a significant negative correlation between hit rate and N170 amplitudes for patients only (Table 4), which means larger N170 in patients predicted better performance in recognition of family members. There were no significant correlations between the early anterior component and accuracy. There were however significant correlations between late anterior component and accurately rejecting famous and nonfamous faces (Table 4, Fig. 9). Thus, patients who were more accurate had more positive anterior late component, more similar to the controls' waveform. This is compatible with the idea that this late component is associated with the ability to detect and minimize erroneous output during memory retrieval.

\section{Discussion}

The VMPFC appears to serve an important function during memory retrieval, and more specifically in monitoring of retrieval output, but its precise role is yet to be determined. Theories of VMPFC function have suggested it acts to integrate cogni- 
A.
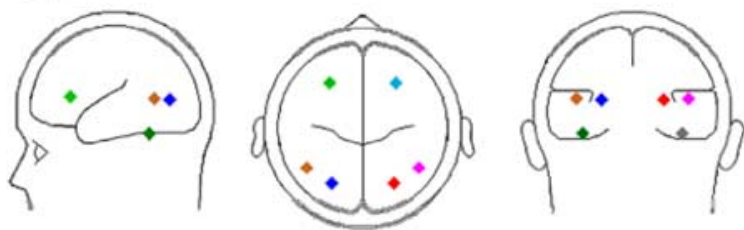

B.

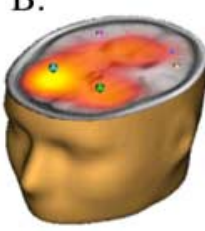

C.
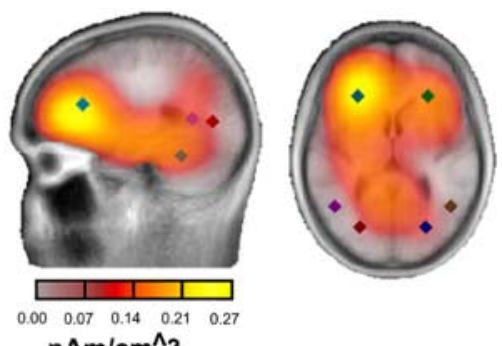

$\mathrm{nAm} / \mathrm{cm}^{\wedge}{ }_{3}$

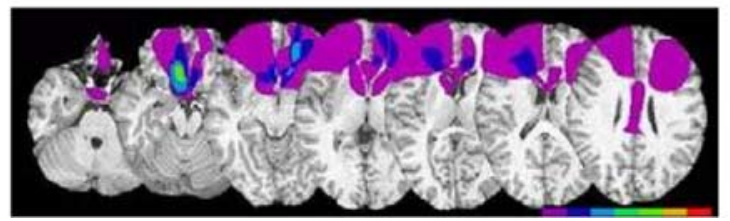

D.
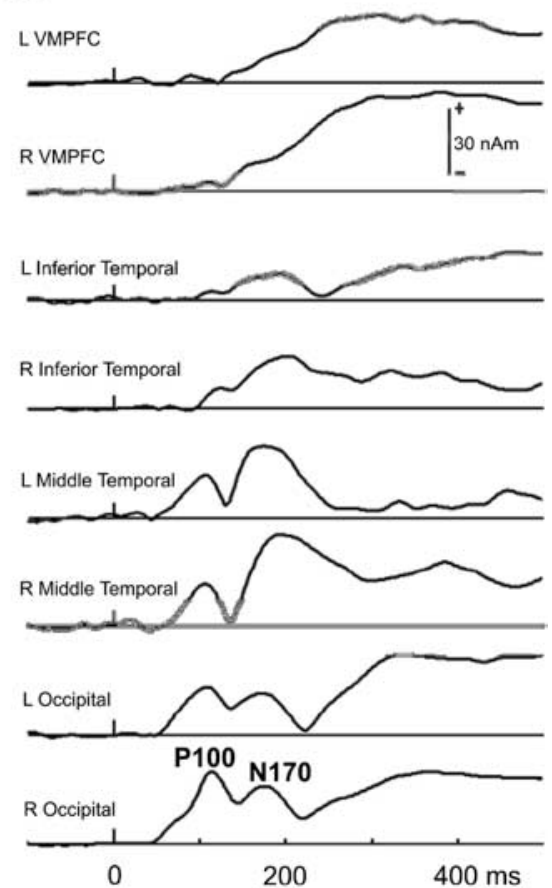

Figure 7. Source analyses for controls' waveforms. $A$, Results of the spatiotemporal multiple source analysis for $230-260$ ms showing the optimal sources in VMPFC (green and light blue) when posterior source locations of earlier evoked responses are fixed. $\boldsymbol{B}$, LAURA distributed source modeling approach located an almost identical source at $245 \mathrm{~ms}$ to bilateral VMPFC. $\boldsymbol{C}$, Both source models correspond to the area of maximum lesion overlap in the patients. $\boldsymbol{D}$, Source waveforms show the time course of source activity over posterior and anterior regions. See Results for details.

Table 3. Correlations between ERPs and reaction times for hits, correct rejections of famous persons, and correct rejections of unfamiliar persons

\begin{tabular}{|c|c|c|c|c|c|c|}
\hline & \multicolumn{2}{|c|}{ Posterior right N170 } & \multicolumn{2}{|c|}{ Anterior early (230 - 260) } & \multicolumn{2}{|c|}{ Anterior late $(450-550)$} \\
\hline & Controls & Patients & Controls & Patients & Controls & Patients \\
\hline Family (hits) & 0.39 & 0.12 & 0.03 & $-0.79^{*}$ & -0.49 & 0.44 \\
\hline Famous (CR) & 0.06 & 0.26 & 0.25 & $-0.68^{*}$ & -0.44 & 0.14 \\
\hline Unfamiliar (CR) & 0.51 & -0.03 & -0.38 & $-0.72^{*}$ & 0.22 & 0.01 \\
\hline
\end{tabular}

${ }_{*_{p}}<0.05$.

tive processes with emotional somatic signals to bias decision making at a preconscious level (Bechara et al., 1997, 2000a,b). Alternatively, its role has been interpreted in terms of learning and reversal of stimulus-reinforcement associations to bias behavior according to individual goals and drives (Rolls et al., 1994; Rolls, 1996, 2004). Either way, the VMPFC is well situated anatomically to integrate limbic information and information from neocortical heteromodal regions, to allow for such biasing (Barbas, 1995). The VMPFC may serve similar functions in the memory domain, predominantly in autobiographical memories where such processes are pertinent (Conway and Pleydell-Pearce, 2000; Fotopoulou et al., 2007).

VMPFC patients in the present study lacked a positive deflection at 230-260 ms after stimulus onsets that receive input from VMPFC as suggested by source modelings in controls. Furthermore, patients who showed larger positive deflections were faster on their accurate memory decisions, consistent with the idea that this early electrophysiological signature is related to rapid selec-

A. each of the patients.

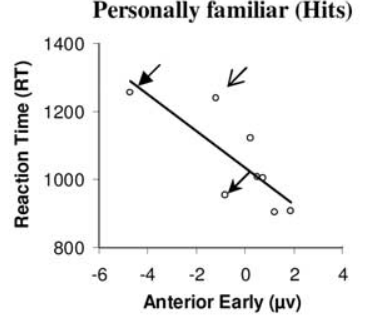

B.

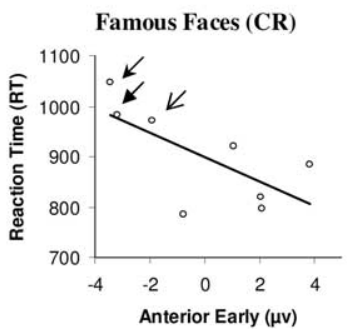

C.

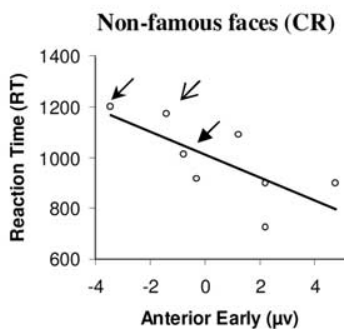

Figure 8. Correlations between reaction times for hits of acquaintances $(\boldsymbol{A})$, correct rejection of famous $(\boldsymbol{B})$ and nonfamous $(\boldsymbol{C})$ faces, and mean amplitude at $230-260 \mathrm{~ms}$ after stimulus onset over anterior electrodes (FPz, FP1, FP2) for patients. Arrows mark the data points corresponding to the three patients with confabulation or a history of confabulation with unique arrowheads for

tion of memory-based responses. In the same way, patients with history of confabulation had the most negative waveforms and took longer to make correct responses. Schnider et al. (2002) have proposed an intriguing model in which the VMPFC plays a role in rapid filtering of memories according to their relevance to current reality. They report a positive frontally distributed ERP deflection also peaking at $240 \mathrm{~ms}$ during a memory condition known to be sensitive to confabulation (Schnider et al., 2002; Schnider, 2003). Although their ERP study only included healthy 
Table 4. Correlations between ERP's and reaction times for hits, correct rejections of famous persons, and correct rejections of unfamiliar persons

\begin{tabular}{|c|c|c|c|c|c|c|}
\hline & \multicolumn{2}{|c|}{ Posterior right N170 } & \multicolumn{2}{|c|}{ Anterior early $(230-260)$} & \multicolumn{2}{|c|}{ Anterior late $(450-550)$} \\
\hline & Controls & Patients & Controls & Patients & Controls & Patients \\
\hline Family (hits) & 0.44 & $-0.62^{*}$ & -0.30 & 0.46 & -0.42 & 0.49 \\
\hline Famous (CR) & & -0.13 & & -0.08 & & $0.76^{*}$ \\
\hline Unfamiliar (CR) & & 0.48 & & -0.25 & & $0.92^{* *}$ \\
\hline
\end{tabular}

${ }^{*} p<0.05 ;{ }^{* *} p<0.01$.

A.

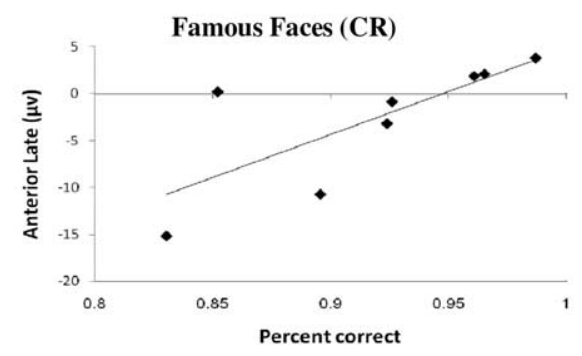

B.

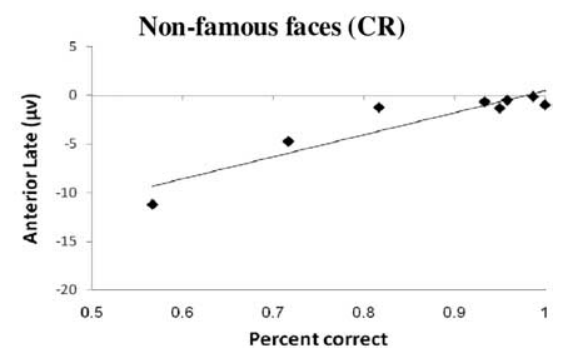

Figure 9. Correlations between accuracy for correct rejection of famous $(\boldsymbol{A})$ and nonfamous $(\boldsymbol{B})$ faces and mean amplitude at 450 -550 ms after stimulus onset over anterior electrodes (FPz, FP1, FP2) for patients.

controls, confabulating patients always fail this condition, which is considered a sign of temporal context confusion (TCC), i.e., a failure of a rapid filtering mechanism for currently irrelevant memory traces. According to their model, this filtering mechanism acts by momentarily inhibiting cortical synchronization at a preconscious stage, before explicit recognition occurs. When filtering fails, people might act according to memory representations that are no longer relevant and behavioral confabulations may arise.

The data from the present study are consistent with our dualmonitoring hypothesis, which suggests an early postecphoric, very early feeling of rightness (FOR) mechanism providing an immediate general sense of the correctness of memory decisions (Gilboa and Moscovitch, 2002; Moscovitch and Winocur, 2002; Gilboa, 2004; Gilboa et al., 2006). The neurocognitive mechanism underlying the early memory-related ERP waveforms observed in the present study and in that of Schnider et al. (2002) might be analogous. In the present study, however, the task has no temporal component, which suggests that the filtering mechanism might serve a more general function than supporting the representation of current reality and in fact helps make any finegrained distinctions within memory [see Gilboa et al. (2006) for more evidence and discussion of this point]. Furthermore, as discussed below, we present evidence that the early frontal modulation follows an earlier (preconscious) familiarity signal when remote memories are retrieved, although it precedes explicit recognition as suggested by Schnider et al. (2002). Importantly, we show that patients with VMPFC lesions lack that early frontal modulation, as predicted by both models. Interestingly some nonconfabulating patients with VMPFC lesions also fail on Schnider's task (Gilboa et al., 2006) and it may be that this is related to individual differences in this early electrophysiological signature.

Very few electrophysiological studies of memory with neurological patients exist, and even fewer involve patients with focal lesions. In focal MTL anterograde amnesia, modulations of the posterior late positivity component (LPC/P600) old-new effect have been described (Olichney et al., 2000). Similar results were obtained in amnesics with diffuse damage following anoxia (Mecklinger et al., 1998), although these patients showed no LPC old-new or even inverted effects and also had alterations in earlier non-mnemonic ERP components (P300, N400). In contrast, a study of patients with focal dorsolateral PFC lesions using a continuous recognition paradigm (Swick and Knight, 1999) showed no difference in ERP waveforms compared with controls, despite behavioral difference which were manifested primarily as increase in false alarms.

Unlike these previous studies we examined retrograde semantic memory which is poorly correlated with anterograde episodic amnesia. Furthermore, our patients are not amnesic; they suffer from some anterograde memory impairments, and did not perform as well on the experimental retrograde task, but do not meet criteria for amnesia. They do however show deficits on aspects of "working with memory" such as susceptibility for interference, intrusions, and false alarms. These distinctions might account for the differences in the patterns of ERP results between our study and previous studies of amnesic patients, in particular the very early memory related differences over the posterior N170 and the positive anterior modulation at $230-260 \mathrm{~ms}$. In contrast, the later differences observed in the present study might be interpreted either as reflecting later monitoring processes, as suggested by the correlation with accuracy, or as a failure in recollective processes as suggested by previous ERP studies (Taylor and Olichney, 2007). The late monitoring component of our model operates by bringing other relevant information to bear on the recovered memory, such as perceptual characteristics and compatibility with other knowledge which could influence the decision to accept or reject the recovered memory. This process may rely heavily on recollection of additional information for verification, and so the interpretations of the late ERP difference might converge.

Another interesting feature of the present study was a very early group-by-condition interaction associated with the well studied N170 component of face processing (Bentin and Deouell, 2000; Caharel et al., 2002, 2006, 2007; Rossion and Gauthier, 2002; Jemel et al., 2003, 2005; Itier and Taylor, 2004; Anaki et al., 2007; Marzi and Viggiano, 2007). Our healthy controls showed a familiarity effect regardless of whether the face was personally familiar or a famous face, and whether it was explicitly recognized. This suggests that at a preconscious level information about faces of acquaintances that were not consciously recognized was available, similar to the effects seen in covert recognition of faces using psychophysiological measures such as skin conductance (Tranel and Damasio, 1985; Calder and Young, 2005). There was no such differential modulation of the N170 in the patients. We have proposed (Gilboa, 2004; Gilboa et al., 2006) that the basis of FOR may be a correspondence between a retrieval cue and representations in LTM, with stronger representations (as in self-related processing, for example) generating more robust FOR. 
The familiarity modulation of the posterior N170 which appeared $\sim 70$ ms before the early anterior difference between the groups may have formed the basis of early monitoring in controls which was diminished or undifferentiated in patients.

It should be noted that the sensitivity of N170 to face identity is a contentious issue. Many studies show no modulation of N170 in response to familiarity (Bentin and Deouell, 2000; Eimer, 2000; Schweinberger et al., 2002; Anaki et al., 2007), while others show the same effect observed in the present study (Caharel et al., 2002, 2006; Schweinberger et al., 2002; Jemel et al., 2003; Marzi and Viggiano, 2007). The effect appears to be particularly observable under conditions of degraded stimuli and when familiarity is important for task performance. Both features characterize our study which included many low quality stimuli and which required participants to make fine distinctions between different kinds of familiarity (personal vs public), which may emphasize the top-down contribution of LTM in disambiguating face identity.

The absence of modulation of the posterior N170 in patients with anterior lesions is interesting, although not surprising. Early ERP work has shown differences in ERP waveform between patients with DLPFC lesions and controls during auditory perceptual tasks (Woods and Knight, 1986), suggesting that top-down modulations may occur very early and preconsciously. Frontal top-down control over visual perceptual processes have been demonstrated, particularly when ambiguity had to be resolved regarding object identity (Bar et al., 2006). The missing N170 familiarity signature in patients may contribute to the lack of early anterior positive modulation and consequently for reliance on later more elaborate processing of the stimuli to reach a decision.

To conclude, we believe the present data are consistent with a model in which the compatibility of a memory cue with LTM representations is picked up by posterior cortices (indexed by the N170) and serves as a basis for the formation of an early VMPFCmediated FOR. Deficits in FOR following VMPFC lesions are akin to deficits in extinction and reward association reversal in non-mnemonic domains in that they too reflect contextinsensitive responses and are impenetrable to rationality or explicit knowledge. Interestingly, VMPFC lesions appear to disrupt not only FOR but also the posterior familiarity index possibly through top-down control. In healthy adults, the posterior familiarity index is also related to later anterior processes, whereas patients with VMPFC lesions do not show such an association and appear to recruit different elaborate processes to achieve accurate performance.

\section{References}

Anaki D, Zion-Golumbic E, Bentin S (2007) Electrophysiological neural mechanisms for detection, configural analysis and recognition of faces. Neuroimage 37:1407-1416.

Bar M, Kassam KS, Ghuman AS, Boshyan J, Schmid AM, Dale AM, Hämäläinen MS, Marinkovic K, Schacter DL, Rosen BR, Halgren E (2006) Top-down facilitation of visual recognition. Proc Natl Acad Sci U S A 103:449-454

Barbas H (1995) Anatomic basis of cognitive-emotional interactions in the primate prefrontal cortex. Neurosci Biobehav Rev 19:499-510.

Bechara A, Damasio H, Tranel D, Damasio AR (1997) Deciding advantageously before knowing the advantageous strategy [see comments]. Science 275:1293-1295.

Bechara A, Damasio H, Damasio AR (2000a) Emotion, decision making and the orbitofrontal cortex. Cereb Cortex 10:295-307.

Bechara A, Tranel D, Damasio H (2000b) Characterization of the decisionmaking deficit of patients with ventromedial prefrontal cortex lesions. Brain 123:2189-2202.
Bentin S, Deouell LY (2000) Structural encoding and identification in face processing: ERP evidence for separate mechanisms. Cogn Neuropsychol 17:35-54.

Brewer WF (1986) What is autobiographical memory? In: Autobiographical memory (Rubin DC, ed). New York: Cambridge UP.

Burgess PW, Shallice T (1996) Confabulation and the control of recollection. Memory 4:359-411.

Caharel S, Poiroux S, Bernard C, Thibaut F, Lalonde R, Rebai M (2002) ERPs associated with familiarity and degree of familiarity during face recognition. Int J Neurosci 112:1499-1512.

Caharel S, Fiori N, Bernard C, Lalonde R, Rebaï M (2006) The effects of inversion and eye displacements of familiar and unknown faces on early and late-stage ERPs. Int J Psychophysiol 62:141-151.

Caharel S, Bernard C, Thibaut F, Haouzir S, Di Maggio-Clozel C, Allio G, Fouldrin G, Petit M, Lalonde R, Rebaï M (2007) The effects of familiarity and emotional expression on face processing examined by ERPs in patients with schizophrenia. Schizophr Res 95:186-196.

Calder AJ, Young AW (2005) Understanding the recognition of facial identity and facial expression. Nat Rev Neurosci 6:641-651.

Conway MA, Pleydell-Pearce CW (2000) The construction of autobiographical memories in the self-memory system. Psychol Rev 107:261-288.

DeLuca J, Diamond BJ (1995) Aneurysm of the anterior communicating artery: a review of neuroanatomical and neuropsychological sequelae. J Clin Exp Neuropsychol 17:100-121.

Eimer M (2000) Effects of face inversion on the structural encoding and recognition of faces. Evidence from event-related brain potentials. Brain Res Cogn Brain Res 10:145-158.

Fletcher PC, Henson RN (2001) Frontal lobes and human memory: insights from functional neuroimaging. Brain 124:849-881.

Fotopoulou A, Conway MA, Solms M (2007) Confabulation: motivated reality monitoring. Neuropsychologia 45:2180-2190.

Gilboa A (2004) Autobiographical and episodic memory-one and the same? Evidence from prefrontal activation in neuroimaging studies. Neuropsychologia 42:1336-1349.

Gilboa A, Moscovitch M (2002) The cognitive neuroscience of confabulation: a review and a model. In: Handbook of memory disorders, Ed 2 (Baddeley AD, Kopelman MD, Wilson BA, eds), pp 315-342. London: Wiley.

Gilboa A, Alain C, Stuss DT, Melo B, Miller S, Moscovitch M (2006) Mechanisms of spontaneous confabulations: a strategic retrieval account. Brain 129:1399-1414.

Guillaume F, Tiberghien G (2005) Electrophysiological study of contextual variations in a short-term face recognition task. Brain Res Cogn Brain Res 22:471-487.

Halgren E, Baudena P, Heit G, Clarke JM, Marinkovic K, Chauvel P, Clarke M (1994) Spatio-temporal stages in face and word processing. 2. Depthrecorded potentials in the human frontal and Rolandic cortices. J Physiol Paris 88:51-80.

Itier RJ, Taylor MJ (2004) N170 or N1? Spatiotemporal differences between object and face processing using ERPs. Cereb Cortex 14:132-142.

Jasper HH (1958) The ten-twenty electrode system of the international federation. Electroencephalogr Clin Neurophysiol 10:371-375.

Jemel B, Pisani M, Calabria M, Crommelinck M, Bruyer R (2003) Is the N170 for faces cognitively penetrable? Evidence from repetition priming of Mooney faces of familiar and unfamiliar persons. Brain Res Cogn Brain Res 17:431-446.

Jemel B, Pisani M, Rousselle L, Crommelinck M, Bruyer R (2005) Exploring the functional architecture of person recognition system with eventrelated potentials in a within- and cross-domain self-priming of faces. Neuropsychologia 43:2024-2040.

Klopp J, Marinkovic K, Chauvel P, Nenov V, Halgren E (2000) Early widespread cortical distribution of coherent fusiform face selective activity. Hum Brain Mapp 11:286-293.

Kopelman M, Wilson B, Baddeley A (1990) The autobiographical memory interview. Bury St Edmunds, England: Thames Valley Test Company.

Koriat A, Goldsmith M, Pansky A (2000) Toward a psychology of memory accuracy. Annu Rev Psychol 51:481-537.

Marzi T, Viggiano MP (2007) Interplay between familiarity and orientation in face processing: an ERP study. Int J Psychophysiol 65:182-192.

Mecklinger A, von Cramon DY, Matthes-von Cramon G (1998) Eventrelated potential evidence for a specific recognition memory deficit in adult survivors of cerebral hypoxia. Brain 121:1919-1935. 
Mesulam MM (2000) Principles of behavioral and cognitive neurology, Ed 2. Oxford: Oxford UP.

Mishkin M, Malamut BL, Bachevalier J (1984) Memories and habits: two neural systems. In: Neurobiology of learning and memory (McGaugh G, Lynch G, Weinberger NM, eds), pp 65-77. New York: Guilford.

Moscovitch M, Winocur G (2002) The frontal cortex and working with memory. In: Principles of frontal lobe function (Stuss DT, Knight R, eds), pp 188-209. New York: Oxford UP.

Olichney JM, Van Petten C, Paller KA, Salmon DP, Iragui VJ, Kutas M (2000) Word repetition in amnesia. Electrophysiological measures of impaired and spared memory. Brain 123:1948-1963.

Picton TW, van Roon P, Armilio ML, Berg P, Ille N, Scherg M (2000) The correction of ocular artifacts: a topographic perspective. Clin Neurophysiol 111:53-65.

Rolls ET (1996) The orbitofrontal cortex. Philos Trans R Soc Lond B Biol Sci 351:1433-1443; discussion 1443-1434.

Rolls ET (2004) The functions of the orbitofrontal cortex. Brain Cogn 55:11-29.

Rolls ET, Hornak J, Wade D, McGrath J (1994) Emotion-related learning in patients with social and emotional changes associated with frontal lobe damage. J Neurol Neurosurg Psychiatry 57:1518-1524.

Rossion B, Gauthier I (2002) How does the brain process upright and inverted faces? Behav Cogn Neurosci Rev 1:63-75.

Rugg MD, Otten LJ, Henson RN (2002) The neural basis of episodic memory: evidence from functional neuroimaging. Philos Trans R Soc Lond B Biol Sci 357:1097-1110.

Schacter DL, Norman KA, Koutstaal W (1998) The cognitive neuroscience of constructive memory. Annu Rev Psychol 49:289-318.
Schnider A (2003) Spontaneous confabulation and the adaptation of thought to ongoing reality. Nat Rev Neurosci 4:662-671.

Schnider A, Valenza N, Morand S, Michel CM (2002) Early cortical distinction between memories that pertain to ongoing reality and memories that don't. Cereb Cortex 12:54-61.

Schweinberger SR, Pickering EC, Jentzsch I, Burton AM, Kaufmann JM (2002) Event-related brain potential evidence for a response of inferior temporal cortex to familiar face repetitions. Brain Res Cogn Brain Res 14:398-409.

Stemmer B, Segalowitz SJ, Witzke W, Schönle PW (2004) Error detection in patients with lesions to the medial prefrontal cortex: an ERP study. Neuropsychologia 42:118-130.

Stuss DT, Alexander MP, Floden D, Binns MA, Levine B, McIntosh AR, Rajah N, Hevenor SJ (2002) Fractionation and localization of distinct frontal lobe processes: evidence from focal lesions in humans. In: Principles of frontal lobe functions (Stuss DT, Knight RT, eds), pp 392-407. New York: Oxford UP.

Swick D, Knight RT (1999) Contributions of prefrontal cortex to recognition memory: electrophysiological and behavioral evidence. Neuropsychology 13:155-170.

Taylor JR, Olichney JM (2007) From amnesia to dementia: ERP studies of memory and language. Clin EEG Neurosci 38:8-17.

Tranel D, Damasio AR (1985) Knowledge without awareness: an autonomic index of facial recognition by prosopagnosics. Science 228:1453-1454.

Woods DL, Knight RT (1986) Electrophysiologic evidence of increased distractibility after dorsolateral prefrontal lesions. Neurology 36:212-216. 